Article

\title{
Telomere Length Diversity in Cattle Breeds
}

Francesca Tilesi $^{1{ }^{1} *} \uparrow$, Enea Gino Di Domenico ${ }^{2,} \uparrow$, Lorraine Pariset ${ }^{3}$, Luigi Bosco ${ }^{1}$, Daniela Willems ${ }^{1}$, Alessio Valentini ${ }^{3}$ and Fiorentina Ascenzioni ${ }^{2}$

1 Department of Ecology and Sustainable Economic Development, Tuscia University, 01100 Viterbo, Italy; E-Mails: willems@unitus.it (D.W.); bosco@unitus.it (L.B.)

2 Department of Cell and Developmental Biology, La Sapienza University of Rome, 00185 Rome, Italy; E-Mails: enea.didomenico@uniroma1.it (E.G.D.); fiorentina.ascenzioni@uniroma1.it (F.A.)

3 Department of Animal Production, Tuscia University, 01100 Viterbo, Italy;

E-Mails: pariset@unitus.it (L.P.); alessio@unitus.it (A.V.)

* Author to whom correspondence should be addressed; E-Mail: francesca.tilesi@ unitus.it; Tel.: +39-761-357-754; Fax: +39-761-357-751.

$\dagger$ These authors contributed equally to this work.

Received: 23 April 2010; in revised form: 26 July 2010 / Accepted: 24 August 2010 / Published: 31 August 2010

Abstract: Telomeres are specialized nucleoprotein structures that have two important functions: (i) protection of the chromosomal ends from deleterious events such as chromosome fusion and degradation; (ii) counteraction of the "end replication problem" by allowing telomerase-dependent or, more rarely, telomerase-independent telomere elongation. The DNA sequences underlying these activities are short simple tandem repeats, which in vertebrate consist of a variable number of TTAGGG. Telomeres dysfunction may be caused either by the absence of telomerase activity or by mutations in telomeric proteins involved in telomere length and structure regulation. Additionally, increasing experimental evidence suggests that telomeres take part in the complex network regulating cell proliferation. Accordingly, telomeres are involved in biological process such as aging and tumor progression. In this study we determined the telomere length in two bovine Italian cattle breeds, Chianina and Maremmana, which are characterized by high longevity and range breeding. In order to account for possible variation among different tissues, we have determined telomere length in different organs such as spleen, lung and liver. Overall, the median telomere length was significant lower in Chianina $(11 \pm 0.69 \mathrm{~kb})$ than in Maremmana (12.05 $\pm 1.57 \mathrm{~kb})$. Moreover, telomere length variation 
among individuals was very low in Chianina but rather high in Maremmana. These data suggest that telomere length is influenced by the breeds. This hypothesis is confirmed by the different history of these Italian breeds. Indeed, Chianina has a long history and its size was maintained by the Breeders Association without necessity to crossbreed with other breeds, whereas the population of Maremmana underwent a dramatic shrinkage in the recent past. Therefore, breeders have crossed Maremmana with other breeds, like Charolais, and have relaxed the rules for the inclusion in the herd book.

Keywords: telomere length; TRF; cattle breed; Chianina; Maremmana

\section{Introduction}

Telomeres are specialized nucleoprotein structures present at the end of eukaryotic chromosomes that have two important functions: (i) to protect the chromosomal ends from recombination and degradation; (ii) to counteract the "end replication problem" by allowing telomerase-dependent or, more rarely, telomerase-independent telomere elongation [1-3]. Telomeres consist of stretches of G-C rich tandem repeats highly conserved throughout evolution, which are composed of variable number of TTAGGG in all vertebrates [4]. Typically, telomeres end up with a single-stranded 3'overhang, the G-tail, varying in length from a few nucleotides in yeast to a few hundred nucleotides in man. Telomeric G-tails have been proposed to be involved both in establishing a closed telomere structure, the T-loop, which precludes the access to telomerase, and in acting as a substrate for telomerase activity leading to telomere lengthening. Thereby, telomere length is the results of two opposing mechanisms: (i) telomere erosion due to unprotected ends that may be degraded and/or incompletely replicated; (ii) telomerase-dependent telomere lengthening. The equilibrium between these processes embodies the mean telomere length. Since the telomerase enzyme is finely regulated during development and it is usually inactive in adult organisms, telomeres are particularly vulnerable, due to progressive shortening at each round of DNA replication, which places the organism at risk of chromosome instability during aging. Indeed, telomere shortening has been documented in aging tissues and hyper-proliferative disease. However, telomerase is reactivated to maintain telomere length allowing unlimited proliferation in most advanced cancers. These data lead to speculate that telomerase activity plays an obligate role in cancer development whereas lack of such activity promotes aging and degenerative disease [5].

Although the contribution of telomere maintenance to aging is still under debate, a number of experimental and clinical studies suggest that telomere maintenance plays an important role in longevity, both in humans and in wild animals [6-8]. In older humans (60- to 97-year-old individuals), a prospective study showed that individuals with short telomeres had higher mortality than those with long telomeres [6] and the survival difference was in part attributable to the individuals with short telomeres having higher mortality from age-related diseases. More recent human studies show no clear association between telomere length and survival in humans older than 85 years of age $[9,10]$ suggesting that telomere length may be a more informative biomarker for mortality in young- and middle-aged individuals rather than in the oldest individuals of a species [11]. Similarly, in wild 
populations it was shown that that longer lived species better maintain their telomeres as compared with shorter lived ones [12], In one species, Leach's storm petrel (Oceanodroma leucorhoa), a long-lived seabird that lives four-times longer than expected based on body mass [13], telomere length did not shorten with age but instead appeared to lengthen across the bird's life span [12]. Additionally, the yearling female tree swallows (Tachycineta bicolor) with shorter than average telomeres were less likely to return to the breeding site in subsequent years than those with longer than average telomere lengths, suggesting that telomere maintenance is not only associated with late-life mortality [8]. These data provide further evidence that telomere maintenance is related to cellular and organism longevity.

The telomere length vary from few hundred bp in yeasts to hundreds of $\mathrm{kb}$ in mammals [2]. Telomere length in several domestic animal species, including sheep, pigs, horses, dogs and cats range from 10 to $30 \mathrm{~kb}$ [14-17], an exception being Mus musculus, which shows very long telomeres of up to $100 \mathrm{~kb}$ [18]. Telomere length in cattle breeds was previously determined but limited to a few breeds. In 2002, Myashita et al. [19] analyzed leukocytes telomeres from Japanese Black cattle (age 1-18 yr), the mean size of the terminal restriction telomere fragments were found to be 19.0-21.0 kb in newborn calves and $16.8-15.1 \mathrm{~kb}$ in 18-yr-old animals. Telomere shortening during aging in cows was confirmed by a subsequent study [18] showing that telomere length from ear fibroblasts was $19.5 \pm 0.5 \mathrm{~kb}$ in seven-year old adult cows and $18.5 \pm 0.5 \mathrm{~kb}$ in 10-year-old-cows, but no prospective study of telomere length in cattle breeds having different breeding history was published yet.

In this study we present the analysis of telomere length in three different tissues, characterized by different proliferation capacity: spleen, lung and liver. The samples were from two Italian cattle breeds, Chianina and Maremmana, which are both characterized by high longevity and free range breeding.

The Maremmana breed can be traced back to Grey Steppe cattle, which entered Italy in large numbers during the 14th to 18th centuries. Herdbook registration started in 1935 (total breed population 274,000 heads). Since 1945 , head numbers have declined dramatically, due to changes in land use and mechanization, and by the mid 1960s extinction was predicted. The breed recovered between 1965 and 1975 because of its ability to adapt to the environmental constraints of the hilly areas of the Maremma, reaching 60,000 heads in 1975. In 1992, 10,000 heads, of which 4,000 were female cows and 120 were sires, were registered in the Herdbook. Since then the number remained constant.

Chianina is one of the oldest cattle breeds in the world. This ancient breed has been raised for over 22 centuries and it is indigenous to Val di Chiana, the fertile plain in central Italy located between the regions of Tuscany and Umbria, which gave the breed its name. It then spread throughout all the provinces in Central Italy and, following World War II, it also crossed the ocean to South America, Australia, Canada and the United States. In 2006, the Italian Chianina population consisted of approximately 33,000 animals in 941 herds. Cows and yearling heifers represent nearly $60 \%$ of the total population; calves and bulls represent $38.5 \%$ and $1.5 \%$ of the population, respectively [20]. 


\section{Experimental Samples}

\subsection{Animal Populations}

In this study, 10 bulls from Chianina (mean age at slaughtering of $18.7 \pm 1.7$ months) and eight from Maremmana (mean age at slaughtering of $20 \pm 1.8$ months) were tested. The bulls, all registered in the Herdbook, were chosen by ANABIC (Associazione Nazionale Allevatori Bovini Italiani da Carne, S.Martino in Colle, Perugia, Italy) in order to ensure the breed standard, and were sampled in different farms of the Lazio region (central Italy) during a six months period (June-December 2006). For all sampled animals the "longevity index" was calculated by ANABIC by using a number of parameters based on family longevity and number of mother's calving. From each animal, liver, spleen and lung tissues were sampled.

\subsection{DNA Isolation and Telomeric Restriction Fragment (TRF) Analysis}

\subsubsection{Genomic DNA Isolation and Digestion}

Genomic DNA was extracted from bovine liver, spleen, and lung. Bovine tissue samples were shock-frozen in small pieces in liquid nitrogen and stored at $-80{ }^{\circ} \mathrm{C}$. Extraction was done from about 10 cryostat sections of $20 \mu \mathrm{m}$ thickness by using Wizard Genomic Purification kits (Promega, Medison, USA) according to the supplier's instructions.

After extraction, the integrity of undigested DNA was analyzed by conventional electrophoresis in 0.8 agarose gel, only samples showing high molecular weight DNA (>23 kb) were used for TRF analysis. TRF analysis was carried out as described in Fradiani et al. [16]. Briefly, $10 \mu \mathrm{g}$ DNA samples were digested with two 4 bp-cutting restriction enzymes, HinfI and Sau3A, and separated by conventional gel electrophoresis $(0.8 \%$ agarose gels, $0.5 \mathrm{~V} / \mathrm{cm}$, run time $18 \mathrm{hr}$ ) and by PFGE (Pulsed Field Gel Electrophoresis) using the following FIGE (Field Inversion Gel Electrophoresis) conditions: $1 \%$ agarose gel in $0.5 \times \mathrm{TBE}$; forward voltage $9.0 \mathrm{~V} / \mathrm{cm}$, reverse voltage $6.0 \mathrm{~V} / \mathrm{cm}$; initial switching time $0.005 \mathrm{~s}$, final switching time $0.92 \mathrm{~s}$; running temperature $14{ }^{\circ} \mathrm{C}$; running time $14 \mathrm{~h}$. PFGE was done using the CHEF-Mapper DRII apparatus (Bio-Rad Laboratories, Inc.).

\subsubsection{Southern Transfer and Hybridization}

The gels were blotted onto nitrocellulose membranes (Scheicher \& Schuell) and hybridized to the $\left(\mathrm{T}_{2} \mathrm{AG}_{3}\right)_{10}$ probe. After washing, hybridization signals were detected using Thypoon 9200 (Amersham Biosciences).

\subsubsection{TRF Analysis}

TRFs were analyzed using densitometry (Kodak ID, Imaging Software) to determine the size distribution of the telomere population in each sample. First, each sample was analyzed using the lane analysis option of the Kodak ID software. The longest and the shortest telomeres were identified as those fragments showing signals above background: either upper or lower background. 
Second, telomere length distribution in each sample was determined by plotting the cumulative fraction of telomeres versus size; the size at which the cumulative fraction equals 0.5 represents the median length, where $50 \%$ of the telomeres are longer and $50 \%$ are smaller than that size [21]. This analysis was done by using TELORUN, freely available at: http://www4.utsouthwestern.edu/cellbio/ shay-wright/researsh/sw-lab-methods.htm. $\lambda$ and $\lambda$ HindIII DNAs were used as molecular weight markers.

\subsection{Statistical Analysis}

Statistical analysis was performed by paired $T$ student test using GraphPad Prims5.

\section{Results and Discussion}

Since previous studies in humans and wild animals suggested that telomere maintenance is not only associated with late-life mortality and that telomere length may be a more informative biomarker for mortality in young- and middle-aged individuals rather than in the oldest individuals of a species, it is reasonable to surmise that telomere length variation may also correlate with longevity of beef cattle. Thereby, we determined the telomere length in two Italian cattle breeds Chianina and Maremmana, which are both characterized by high longevity and free range breeding. However, Maremmana had an abrupt decline in the mid twentieth century due to preference for more industrialized breeds, from which the population recovered by changing breeding policies.

Telomeres are heterogeneous in length for at least two reasons: at the single cell level, telomeres are heterogeneous in size since their length results from the equilibrium between lengthening and shortening events; at the tissue level, telomere length is variable because cells descend from stem cells of different replicative history [22,23]. Telomere length may be accurately determined by using the telomere restriction fragment (TRF) assay, which was proven to be one of the most powerful and informative telomere length analysis methods because it allows for the measurement of a population of telomeres for each individual and in different tissues [24]. Measurement of the entire population of telomeres within a sample of cells is termed genome-wide telomere length [24] or global telomere length [25] and offers information on telomere variability within individuals from one species and eventually among different species [24]. Other useful information comes from plotting the fraction of telomeres as a function of size (cumulative fraction), which allows determination of the median telomere length as the length where half of the telomeres are longer and half are shorter than that size. $[21,26]$. In this study, for each sample we determined the size of the longest and the shortest telomere. Additionally, we determined the telomere fractional size distribution and the median length. These analyses were performed in animals belonging to each breed. Additionally, to account for possible telomere length variation due to regenerative capacity of adult tissues, we tested the following tissues: liver, lung and spleen. Genomic DNAs isolated from each tissue was first checked for DNA integrity by conventional agarose gel electrophoresis in order to exclude those preparations containing fragmented DNA. Subsequently, each DNA was digested with a mixture of two 4 bp-cutting restriction enzymes that cut out the terminal telomeric repeats (TRF) [16,27]. At first, TRFs were analyzed by conventional gel electrophoresis but they migrated as compressed smeared bands ranging in size from $23-25 \mathrm{~kb}$ to $10 \mathrm{~kb}$ in almost all the samples analyzed. Even so, Maremmana TRFs appeared more 
variable in length than the corresponding Chianina TRFs. An example of this is reported in Figure 1 showing a comparative TRF analysis of lung tissues belonging to three different Chianina and Maremmana animals.

Figure 1. Analysis of telomeres in lung samples from three different Chianina (CHN) and Maremmana (MRM) animals. Genomic DNA was digested with a mixture of restriction enzymes and separated by conventional agarose gel electrophoresis. The filter was hybridized to the telomeric probe $\left(\mathrm{C}_{3} \mathrm{TA}_{2}\right)_{3}$. $\mathrm{M}, \lambda$ Hind III size marker (in $\mathrm{kb}$ ).

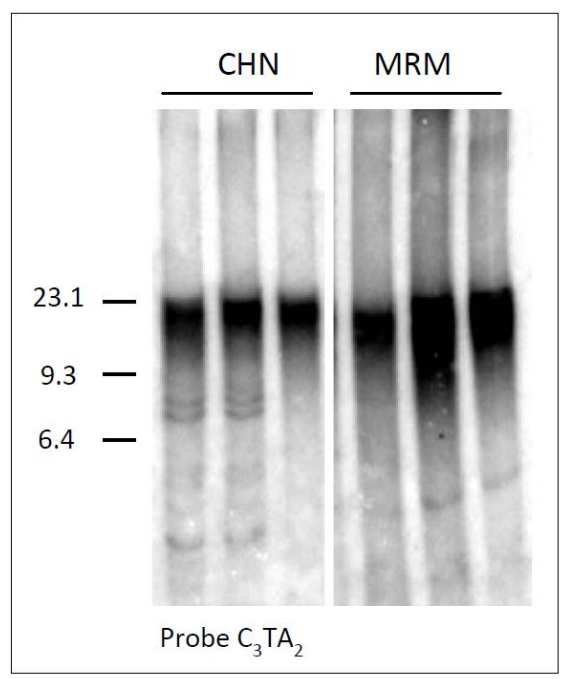

To analyze Chianinas and Maremmana telomeres at higher power resolution, we separated the digested DNA by PFGE, which allows better sizing of DNA fragments in the region of interest. Thereby, liver, spleen and lung DNA samples from different animals belonging to each breed were separated by FIGE (Field Inversion Gel Electrophoresis) as described in the experimental section, and hybridized to a telomeric probe. An example of these analyses is reported in Figure 2.

Figure 2. Telomere length in CHN and MRM samples. Genomic DNAs from liver (Li), spleen (S) and lung (Lu) of two Chianinas (CHN 1 and 2) and two Maremmanas (MRM 1 and 2), were digested, separated by FIGE and hybridized to the telomeric probe $\left(\mathrm{C}_{3} \mathrm{TA}_{2}\right)_{3}$. $\mathrm{M}, \lambda$ Hind III size marker (in $\mathrm{kb}$ ).

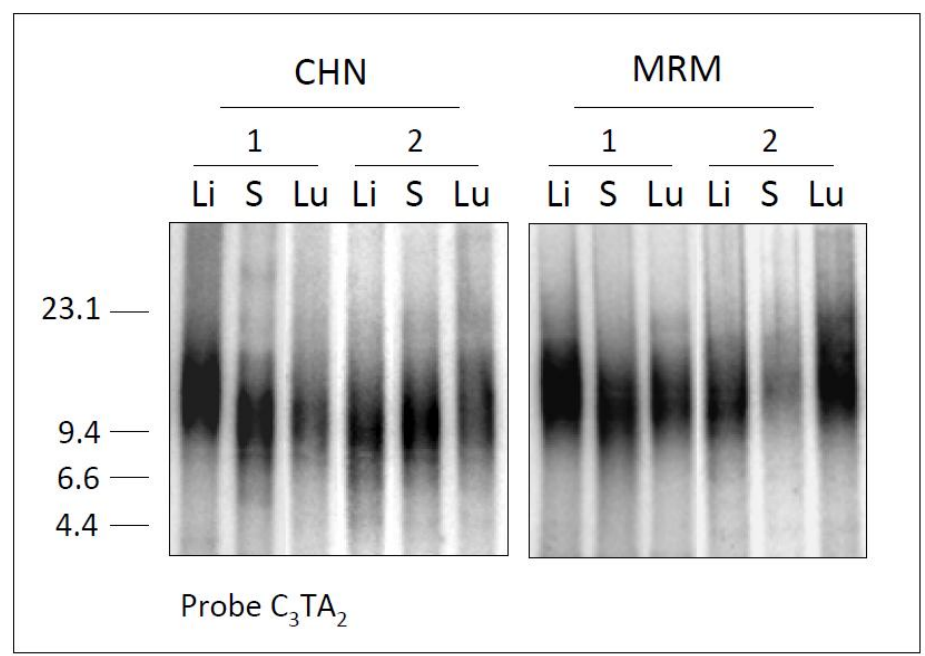


Telomere gels were run with all the samples and the resulting hybridization profiles were analyzed by densitometry. First, by using the lane analysis option of Kodak ID software, we identified the longest and the shortest telomeres as those fragments that were above the upper and lower backgrounds, respectively (Figures 3A and 3B). Overall, it emerged that Chianina telomeres were comprised of a narrow size range with respect to Marammana, and that the former were shorter than the latter.

Figure 3. TRFs analysis by densitometry. A) right side: telomere gel with liver (Li), spleen (S) and lung $(\mathrm{Lu})$ samples from a Maremmana cow; left: densitometric analysis of the resulting telomeric profile. Peaks at $23 \mathrm{~kb}, 9.4 \mathrm{~kb}$ and $6.5 \mathrm{~kb}$ represent molecular weight markers; the numbers to the left refer to the multiple boxes used to scan the intensity of the signal over the lanes. B) box plot representing the length of the shortest (filled square) and the longest (empty square) telomeres of each sample analyzed.

A)

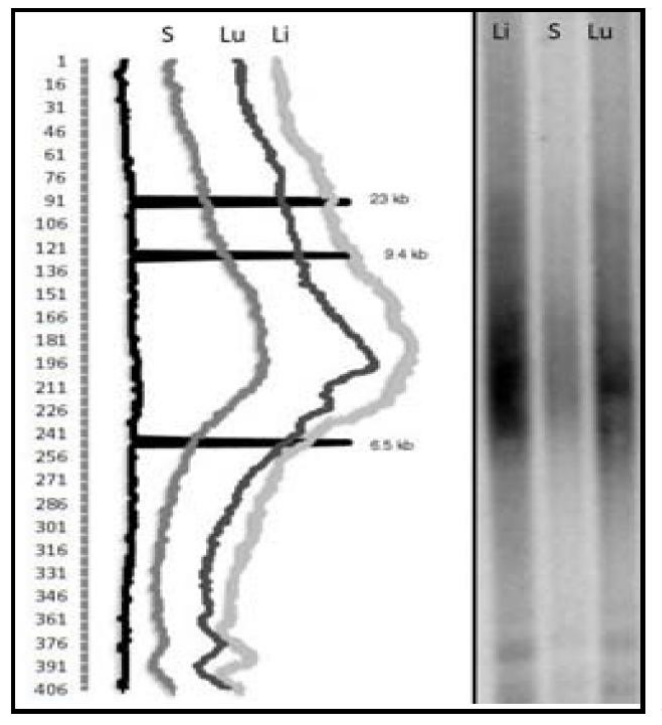

B)

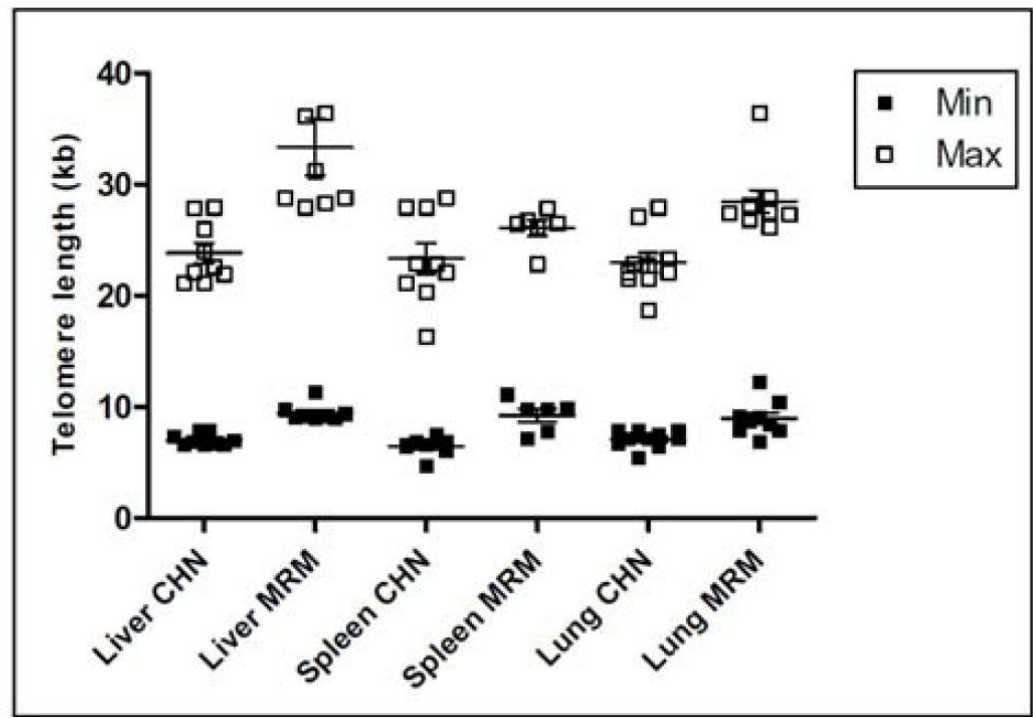

Subsequently, by using the TELORUN program, we plotted the fraction of telomeres as a function of size in all samples from both breeds and the resulting data were analyzed all together according to tissue and breed origin (Figure 4). From this analysis, it is evident that liver and lung telomeres have a different size distribution in the two breeds as demonstrated by the fact that the corresponding curve did not overlap (Figure 4A and C). In contrast, spleen samples from both breeds showed very similar sizes, yielding two almost overlapping curves (Figure 4B). Overall, when Chianina and Maremmana telomeres were analyzed all together, independently from the tissue of origin, two distinct fractional curves were obtained (Figure 4D). Another parameter that contributes to describe telomere populations is the median length, which was easily determined from the fractional curve of each sample. The resulting data showed that the median length of telomeres in Chianina and Maremmana tissues were as follows: (i) CHN liver 11.28 \pm 0.062 , MRM liver $12.90 \pm 0.52$, ( $<<0.05$ ); (ii) CHN lung $11.38 \pm 0.18$, MRM lung $12.16 \pm 0.73$; (iii) CHN spleen $10.68 \pm 0.52$, MRM spleen $10.70 \pm 0.47$. Overall, the median length of telomeres was significantly longer in Maremmana $(12.05 \pm 0.43$; $\mathrm{P}<0.05)$ than in Chianina $(11.0 \pm 0.19)$, although this difference was mainly due to telomere length variation in liver. 
Figure 4. The size distribution of telomeres in the indicated tissues was calculated and expressed as a cumulative fraction versus size (see Experimental methods) the resulting distribution curves in liver (A), lung (B) and spleen (C) from Chianina and Maremmana cattle breeds by using Telorun program. In (D), distribution curves from liver, spleen and lung were analyzed together.
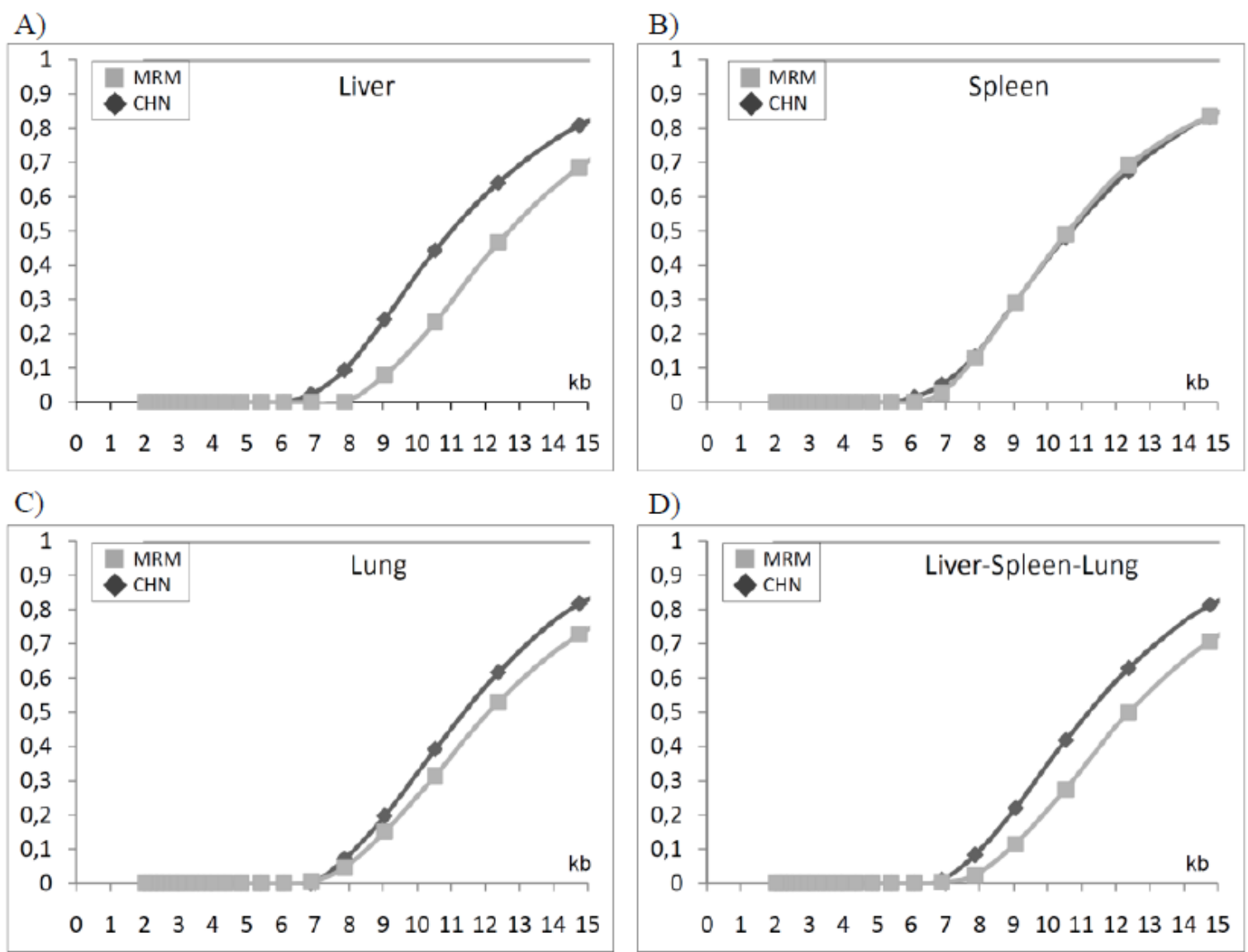

The length of the shortest telomeres is particularly informative since it defines the limit of telomere length under which a telomere may lose its activity and thereby does not guarantee chromosome stability. Overall, the shortest telomereswere $6.79 \pm 0.15 \mathrm{~kb}$ in Chianina and $9.39 \pm 0.27 \mathrm{~kb}$ in Maremmana $(\mathrm{P}<0.001)$ (Figure 5). This results is in agreement with previously published data showing that telomeres $6 \mathrm{~kb}$ in length are critically shorter in human and in birds [26,28], additionally it demonstrates that Maremmana breed's shortest telomeres are significantly longer than that from Chianina. Also, the longest telomere length different significantly between these breeds: in Chianina the maximal length observed was $23.37 \pm 0.59 \mathrm{~kb}$, in Maremmana $29.54 \pm 1.1 \mathrm{~kb}(\mathrm{P}<0.001)$ (Figure 5). 
Figure 5. Distribution of telomere length by Chianina (CHN) and Maremmana (MRM) breeds. Measured $(\mathrm{kb})$ includes the shortest telomere length $\mathbf{A})$ and the longest telomere length B).

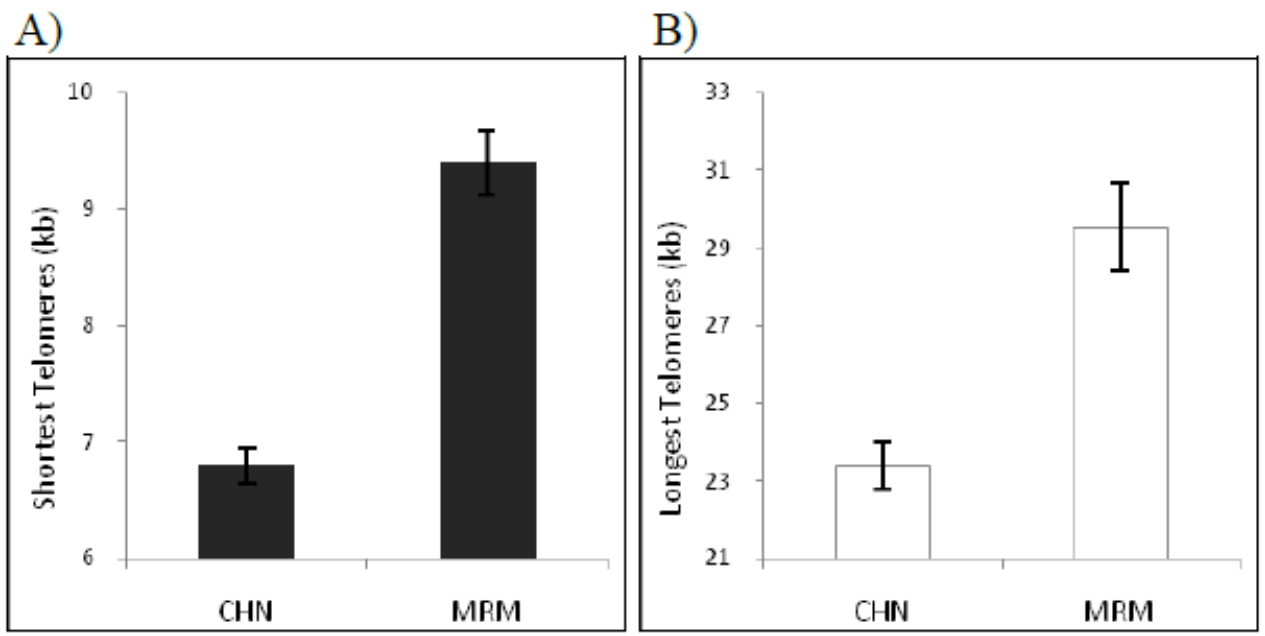

\section{Conclusions}

For the first time to our knowledge, we have shown that telomere length variation is related to cattle breed and that Chianina and Maremmana differ in the lengths and distribution of their telomere size. Telomere length in two (liver and lung) out of three tissues analyzed, as determined by TRFs and analyzed by cumulative fraction, were longer in Maremmana than Chianina. Additionally, liver telomeres were longer than those observed in spleen and lung in both breeds, suggesting that liver may benefits from having longer telomeres since it allows a higher number of cell duplications without the requirement of telomerase reactivation. In the future, it would be interesting to analyze the level of telomerase activity in the same samples to study the relationship between telomere length and telomerase activity in adult somatic cells from tissues with different proliferative capacity.

Since telomere length is an heterogeneous parameter and the average length may not sufficiently describe the genome-wide telomere population, we have taken into consideration three values for the analysis of variance: the size of the longest and the shortest telomeres and the median size of the telomeres which represents the value at which half of the telomeres are longer and half are shorter. In two out of the three tissues analyzed, Maremmana breed showed significantly longer telomeres than Chianina. To explain this result, we hypothesize that telomere length reflects the different history of these Italian breeds. In fact, Chianina has a long history and its size was maintained by the Breeders Association without a necessity for crossbreeding, whereas Maremmana, underwent a dramatic shrinkage in the number of heads in the recent past. Therefore, breeders have crossed Maremmana with other breeds, like Charolais, and have relaxed the rules for the inclusion in the herd book. Additionally, it has to be considered that Maremmana is a breed characterized by rusticity, longevity and capacity to thrive in harsh environments, while Chianina has been actively selected in the last 50 years for meat traits and speed of growth. It is quite difficult at the moment to ascertain if the differences are due to intrinsic characteristics of the breeds established before artificial selection or if they should be attributed to a possible founder effect that by chance picked up a group of ancestors with shorter telomeres. The last hypothesis may have less chance to be true because the within breed 
variability is of the same order of magnitude. Currently, high density SNP panels are been developed for Bos Taurus and in the next future it will be possible to use genome association around the telomerase genes and the genes involved in telomere length regulation to determine if there are selection signatures [29]. Liver telomeres were the longest among the analyzed tissues when only considering maximum length. However, for all length parameters, liver showed the higher variability among tissues. Therefore, it cannot be ruled out by the data collected or by our experiments if the other length parameters are higher in liver than in the other tissues.

\section{Acknowledgements}

The authors wish to thank Gabriella Porcai and Paolo Ciorba for expert technical assistance and Enrica Oddo for sampling and DNA extraction. The research was partially carried out by funds of Regione Lazio PRAL2003 project "Valorizzazione e sviluppo dell'allevamento bovino di razze locali nel Lazio attraverso la caratterizzazione genetica per la resistenza alle malattie, per la longevità e per la qualità della carne".

\section{References}

1. Harley, C.B.; Futcher, A.B.; Greider, C.W. Telomeres shorten during ageing of human fibroblasts. Nature 1990, 31, 458-460.

2. Greider, C.W. Telomere length regulation. Annu. Rev. Biochem. 1996, 65, 337-365.

3. Blakburn, E.H. Switching and signalling at the telomere. Cell 2001, 106, 661-673.

4. Moyzis, R.K.; Buckingham, J.M.; Cram, L.S.; Dani, M.; Deaven, L.L.; Jones, M.D.; Meyen, J.; Ratcliff, R.L.; Wu, J.R. A highly conserved ripetitive DNA sequence, (TTAGGG) $)_{\mathrm{n}}$ at the telomeres of human chromosomes. Pro. Natl. Acad. Sci. 1988, 85, 6622-6626.

5. Artandi, S.; DePinho, R.A. Telomeres and telomerase in cancer. Carcinogenesis 2010, 31, 9-18.

6. Cawthon, R.M.; Smith, K.R.; O’Brien, E.; Sivatchenko, A.; Kerber, R.A. Association between telomere length in blood and mortality in people aged 60 years or older. Lancet 2003, 361, 393-395.

7. Joeng, K.S.; Song, E.J.; Lee, K.J.; Lee, J. Long lifespan in worms with long telomeric DNA. Nat. Genet. 2004, 36, 607-611.

8. Haussmann, M.F.; Winkler, D.W.; Vleck, C.M. Longer telomeres associated with higher survival in birds. Biol. Lett. 2005, 1, 212-214.

9. Martin-Ruiz, C.M.; Gussekloo, J.; van Heemst, D.; von Zglinicki, T.; Estendorp, R.G.J. Telomere length in white blood cells is not associated with morbidity or mortality in the oldest old: A population-based study. Aging Cell 2005, 4, 287-290.

10. Bischoff, C.; Petersen, H.C.; Graakjaer, J.; Andersen-Ranberg, K.; Vaupel, J.W.; Bohr, V.A.; Kolvraa, S.; Christensen, K. No association between telomere length and survival among the elderly and oldest old. Epidemiology 2006, 17, 190-194.

11. Baird, D.M. Telomeres. Exp Gerontol. 2006, 41, 1223-1227.

12. Haussmann, M.F.; Winkler, D.W.; O’Reilly, K.M.; Huntington, C.E.; Nisbet, I.C.T.; Vleck, C.M. Telomeres shorten more slowly in long-lived birds and mammals than in short-lived ones. Proc. $R$. Soc. Lond. B Biol. Sci. 2003, 270, 1387-1392. 
13. Haussmann, M.F.; Winkler, D.W.; Huntington, C.E.; Nisbet, I.C.T.; Vleck, C.M. Telomerase activity is maintained throughout the lifespan of long-lived birds. Exp. Geront. 2007, 42, 610-618.

14. Nasir, L.; Devlin, P.; Mckevitt, T.; Rutteman, G.; Argyle, D.J. Telomere lengths and telomerase activity in dog tissues: a potential model system to study human telomere and telomerase biology. Neoplasia 2001, 4, 351-359.

15. Argyle, D.; Ellsmore, V.; Gault, E.A.; Munro, A.F.; Nasir, L. Equine telomeres and telomerase activity in cellular immortalisation and ageing. Mech. Ageing Dev. 2003, 124, 759-764.

16. Fradiani, P.A.; Ascenzioni, F.; Lavitrano, M.; Donini, P. Telomeres and telomerase activity in pig tissue. Biochimie 2004, 86, 7-12.

17. Alexander, B.; Coppola, G.; Perrault, S.D.; Peura, T.T.; Betts, D.H.; King, W.A. Telomere length status of somatic cell sheep clones and their offspring. Mol. Reprod. Dev. 2007, 74, 1525-1537.

18. Jeon, H.Y.; Hyun, S.H.; Lee, G.S.; Kim, H.S.; Kim, S.; Jeong, Y.W.; Kang, S.K.; Lee, B.C.; Han, J.Y.; Ahn, C.; Hwang, W.S. The analysis of telomere length and telomere activity in cloned pigs and cow. Mol. Repr. Devel. 2005, 71, 315-320.

19. Miyashita, N.; Shiga, K.; Yonai, M.; Kaneyama, K.; Kobayashi, S.; Kojima, T.; Goto, Y.; Kishi, M.; Aso, H.; Suzuki, T.; Sakaguchi, M.; Nagai, T. Remarkable differences in telomere lengths among cloned cattle derived from different cell types. Bio. Reprod. 2002, 66, 1649-1655.

20. Forabosco, F; Boettcher, P.; Bozzi, R.; Filippini, F.; Bijma, P. Genetic selection strategies to improve longevity in Chianina beef cattle. Ita. J. Anim. Sci. 2006, 5, 117-127.

21. Ouellette, M.M.; Liao, M.; Herbert, B.S.; Johnson, M.; Holt, S.E.; Liss, H.S.; Shay, J.W.; Woodring, E.; Wright, W.E. Subsenescent telomere lengths in fibroblasts immortalized by limiting amounts of telomerase. J. Biol. Chem. 2000, 14, 10072-10076.

22. Juola, F.A.; Haussmann, M.F.; Dearborn, D.C.; Vleck, C.M. Telomere shortening in a long-lived marine bird: cross-sectional analysis and test of an aging tool. Auk 2006, 123, 775-783.

23. Drummond, M.W.; Balabanov, S.; Holyoake, T.L.; Brummendorf, T.H. Concise review: telomere biology in normal and leukemic hematopoietic stem cells. Stem Cells 2007, 25, 1853-1861.

24. Baird, D.M.; Britt-Compton, B.; Rowson, J.; Amso, N.N.; Gregory, L.; Kipling, D. Telomere instability in the male germline. Hum. Mol. Genet. 2006, 15, 45-51.

25. Rashid-Kolvear, F.; Pintilie, M.; Done, S.J. Telomere length on chromosome 17q shortens more than global telomere length in the development of breast cancer. Neoplasia 2007, 9, 265-270.

26. Haussmann, M.F.; Mauck, R.A. Telomeres and longevity: testing an evolutionary hypothesis. Mol. Biol. Evol. 2008, 25, 220-228.

27. Ascenzioni, F.; Fradiani, P.A.; Donini, P. Telomere length analysis and in vitro telomerase assay. Meth. Mol. Biol. 2004, 240, 123-146.

28. Canela, A.; Vera, E.; Klatt, P.; Blasco, M.A. High-throughput telomere length quantification by FISH and its application to human population studies. Proc. Natl. Acad. Sci. USA. 2007, 104, 5300-5305. 
29. Bovine HapMap Consortium. Genome-wide survey of SNP variation uncovers the genetic structure of cattle breeds. Science 2009, 324, 528-532.

(C) 2010 by the authors; licensee MDPI, Basel, Switzerland. This article is an open access article distributed under the terms and conditions of the Creative Commons Attribution license (http://creativecommons.org/licenses/by/3.0/). 